\title{
Prevalence of Obesity and Extreme Obesity in Children Aged Three to Five Years
}

\author{
Joan C. Lo MD ${ }^{1,2}$, Benjamin Maring, MD², Malini Chandra, MS MBA ${ }^{1}$, Stephen R. Daniels, \\ MD $^{3}$, Alan Sinaiko, MD ${ }^{4}$, Matthew F. Daley, MD $^{5}$, Nancy E. Sherwood, PhD $^{6}$, Elyse 0. \\ Kharbanda, $\mathrm{MD}^{6}$, Emily D. Parker, PhD MPH ${ }^{6}$, Kenneth F. Adams, $\mathrm{PhD}^{6}$, Ronald J. Prineas, \\ MB BS PhD ${ }^{7}$, David J. Magid, MD ${ }^{5}$, Patrick J. O'Connor, MD MPH ${ }^{6}$, and Louise C. \\ Greenspan, MD 8 \\ ${ }^{1}$ Division of Research, Kaiser Permanente Northern California, Oakland CA \\ ${ }^{2}$ Department of Medicine, Kaiser Permanente Oakland Medical Center, Oakland CA \\ ${ }^{3}$ University of Colorado Denver School of Medicine, Denver CO \\ ${ }^{4}$ Department of Pediatrics, University of Minnesota, Minneapolis MN \\ ${ }^{5}$ Institute for Health Research, Kaiser Permanente Colorado, Denver CO \\ ${ }^{6}$ HealthPartners Institute for Education and Research, Minneapolis MN \\ ${ }^{7}$ Division of Public Health Sciences, Wake Forest University School of Medicine, Winston-Salem \\ NC \\ ${ }^{8}$ Department of Pediatrics, Kaiser Permanente San Francisco Medical Center, San Francisco CA
}

\section{Abstract}

Background-Early childhood adiposity may have significant later health effects. This study examines the prevalence and recognition of obesity and severe obesity among preschool-aged children.

\begin{abstract}
Methods-The electronic medical record was used to examine body mass index (BMI), height, sex and race/ethnicity in 42,559 children aged 3-5 years between 2007-2010. Normal or underweight $\left(\mathrm{BMI}<85^{\text {th }}\right.$ percentile); overweight $\left(\mathrm{BMI} 85^{\text {th }}-94^{\text {th }}\right.$ percentile); obesity (BMI $295^{\text {th }}$ percentile); and severe obesity (BMI $\geq 1.2 \times 95^{\text {th }}$ percentile) were classified using the 2000 Centers for Disease Control and Prevention growth charts. Provider recognition of elevated BMI was examined for obese children aged 5 years.
\end{abstract}

Results-Among 42,559 children, $12.4 \%$ of boys and $10.0 \%$ of girls had BMI $₫ 95^{\text {th }}$ percentile. The prevalence was highest among Hispanics (18.2\% boys, $15.2 \%$ girls), followed by blacks (12.4\% boys, $12.7 \%$ girls). A positive trend existed between increasing BMI category and median height percentile, with obesity rates highest in the highest height quintile. The prevalence of severe obesity was $1.6 \%$ overall and somewhat higher for boys compared to girls (1.9\% versus

Correspondence: Joan C. Lo MD, Division of Research, Kaiser Permanente Northern California, 2000 Broadway, Oakland, CA 94612, 510-627-2986 office, 510-627-2573 fax, Joan.C.Lo@kp.org.

Conflicts of Interest: None 
$1.4 \%, \mathrm{p}<0.01)$. By race/ethnicity, the highest prevalence of severe obesity was seen in Hispanic boys (3.3\%). Among those aged 5 years, $77.9 \%$ of obese children had provider diagnosis of obesity or elevated BMI, increasing to $89.0 \%$ for the subset with severe obesity.

Conclusions-Obesity and severe obesity are evident as early as age 3-5 years, with race/ethnic trends similar to older children. This study underscores the need for continued recognition and contextualization of early childhood obesity in order to develop effective strategies for early weight management.

\section{Keywords}

obesity; children; preschool; severe obesity; children

\section{Introduction}

The current pediatric obesity epidemic in the United States ${ }^{1}$ includes approximately 12 million (17\%) children aged 2-19 years, ${ }^{2}$ with obesity defined as body mass index (BMI) at or above the $95^{\text {th }}$ percentile using the year 2000 Centers for Disease Control and Prevention (CDC) BMI-for-age growth charts. ${ }^{3,4}$ While the prevalence of obesity in children appears to have plateaued in recent years, ${ }^{3-5}$ it is now roughly triple what it was three decades ago. ${ }^{6,7}$ Moreover, there is a growing spectrum of severe obesity, previously classified using a threshold of BMI $\geqslant 9^{\text {th }}$ percentile ${ }^{1,8,9}$ but now using the more recently accepted threshold of BMI $\geq 120 \%$ of the $95^{\text {th }}$ BMI percentile ${ }^{10-12}$ adjusted for age and sex. Using these definitions, studies in selected pediatric populations have found that the prevalence of severe obesity in children ranges from $3.8 \%$ to $7.7 \%,{ }^{8,11-13}$ with severe obesity beginning as early as the preschool years. $8,11,12$

The age at which excess weight gain occurs has important implications for child health and development. ${ }^{14}$ The range of normal BMI changes during childhood growth, with values generally lowest during age 4-6 years (adiposity nadir) followed by an increase (adiposity rebound) and subsequent steady rise into the adolescent years. ${ }^{15-17}$ Early adiposity rebound is associated with greater adiposity in mid-childhood, ${ }^{15}, 16$ which, in turn, has been associated with accelerated growth, advanced bone age, earlier pubertal transition and adult obesity. ${ }^{16,18-25}$ In older children, both overweight and obesity contribute to an increased risk of metabolic syndrome, type 2 diabetes, hypertension, dyslipidemia, non-alcoholic steatohepatitis and obstructive sleep apnea. ${ }^{1,26}$ Thus, early recognition of severe obesity is an important step towards preventing long term adverse health consequences.

There are few epidemiologic studies from large healthcare delivery systems examining obesity rates in pre-school aged children. Recent implementation of sophisticated electronic health information technology provides the unique opportunity to monitor onset and progression of overweight and obesity in large community populations, as well as the future ability to link early anthropometric findings to clinical outcomes. The primary objective of this study was to examine anthropometric findings obtained in clinical practice from a large contemporary cohort of children aged 3-5 years to 1) determine the prevalence of obesity and severe obesity and differences by race/ethnicity, sex and stature; 2 ) compare estimates using BMI percentile, $\mathrm{Z}$ score or percentage above the $95^{\text {th }}$ BMI percentile as thresholds for 
extremely high BMI-for age; 3) determine whether children with BMI $\geq 95^{\text {th }}$ percentile were recognized by their provider; and 4) to review the anthropometric records of individuals whose measured weight and/or BMI values were flagged by the CDC growth chart program $^{27}$ as being biologically implausible values ${ }^{28}$ to determine whether these were actually children with extreme obesity.

\section{Methods}

Kaiser Permanente Northern California (KPNC) is a large integrated healthcare delivery system providing care to over three million members in Northern California, of whom approximately $6 \%$ are children under the age of 6 years. This study examines data derived from 42,620 3-5 year old children from a retrospective cohort of 160,300 KPNC children aged 3-17 years who had BMI and blood pressure obtained during a well-child visit between 1/1/2007-12/31/2010. All children had at least six months health plan membership prior to the index visit and received care within three large KPNC sub-regions. The Institutional Review Board at HealthPartners Institute for Education and Research approved the study with ceding of oversight authority by the KPNC Institutional Review Board. A waiver of informed consent was obtained due to the nature of the study.

The electronic medical record was used to obtain information on age, sex, race/ethnicity and measured height and weight, with BMI calculated as weight (kilograms) divided by height (meters) squared. The year $2000 \mathrm{CDC}$ growth charts were used to calculate age and sexspecific BMI, height and weight percentiles and BMI standard deviation (Z) scores using publically available programs provided by the $\mathrm{CDC}{ }^{27}$ Both BMI percentile and the BMI percentage above the $95^{\text {th }}$ BMI percentile were used to categorize higher degrees of obesity, including a threshold of 1.2 times the $95^{\text {th }}$ BMI percentile to define severe obesity. Subsequent outpatient visits and recognition of obesity and/or elevated BMI within the ensuing year were examined using electronic medical record diagnoses (International Classification of Diseases, $9^{\text {th }}$ revision codes 278.00 for obesity, 278.02 for overweight, V85.54 for BMI $295^{\text {th }}$ percentile and V85.53 for BMI $85^{\text {th }}-94^{\text {th }}$ percentile).

We used three primary methods for data validation because of potential errors in height and weight measurements extracted from the electronic medical record. First, we excluded children in whom the height was flagged as a "biologically implausible value" by the CDC program ${ }^{28}(\mathrm{~N}=30)$ and children whose index visit measurement included a height $<61$ centimeters ( 24 inches), weight $<4.5$ kilograms (10 pounds) or BMI $<10 \mathrm{~kg} / \mathrm{m}^{2}(\mathrm{~N}=3)$.

Among the remaining 42,587 children with well-child visit data, we examined growth charts for children flagged with high biologically implausible values for weight and/or BMI $(\mathrm{N}=237)$ and only 14 were found to be erroneous and excluded. Three children with missing BMI percentile due to erroneously high BMI $>150 \mathrm{~kg} / \mathrm{m}^{2}$ were also excluded. Finally, we reviewed growth charts for obese children with BMI or height differing by more than $15 \%$ or weight by more than $20 \%$ per year at a prior or subsequent visit within 2 years (requiring age $\geq 2$ years) who also had an (A) index BMI $\geq 99^{\text {th }}$ percentile, (B) index BMI $\geq 1.2$ times the $95^{\text {th }}$ percentile, (C) index BMI Z score 2.5 or (D) index BMI $95^{\text {th }}-98^{\text {th }}$ percentile with another BMI $<95^{\text {th }}$ percentile $(\mathrm{N}=193)$ of whom only 11 were erroneous and excluded. 
Height, weight or BMI values that were part of a pattern of rapid growth or weight gain persisting over two or more measurements were considered valid. If the anthropometric data provided insufficient information or if no prior/subsequent measurements were available $(\mathrm{N}=35)$, progress note documentation of obesity and/or elevated BMI was also examined.

In total, 430 growth charts were reviewed by a pediatric endocrinologist (LCG) with exclusion of 28 children ( $0.06 \%$ of the entire cohort) due to erroneous or inconsistent values. The final study cohort included 42,559 3-5 year old children.

\section{Statistical Methods}

All analyses were conducted using SAS version 9.1 (SAS Institute, Cary NC). Differences between subgroups were compared using the chi-squared test for categorical data. The Cochrane-Armitage test was used to examine the trend in proportions across categories. Linear regression techniques were used to examine the relationship between median height percentile and BMI percentile category. A p-value of $<0.05$ was considered statistically significant.

\section{Results}

Among the final cohort of 42,559 children, 7,934 (18.6\%) were 3 years, 23,351 (54.9\%) were 4 years, and 11,274 (26.5\%) were 5 years old (Table 1). Half of the cohort $(49.0 \%)$ was female. The cohort was racially and ethnically diverse, consisting of $26.1 \%$ white, $5.9 \%$ black, 24.4\% Hispanic, 21.8\% Asian (including Pacific Islanders), and 21.8\% of other or unknown race/ethnicity. There were 4775 (11.2\%) children who met criteria for obesity, defined by BMI $\searrow 5^{\text {th }}$ percentile. Overall and within each of the age stratum, the proportion with BMI $\geq 5^{\text {th }}$ percentile was slightly but significantly greater for boys than girls (12.4\% versus $10.0 \%$ overall, $\mathrm{p}<0.05$ for all comparisons). The prevalence of obesity was significantly lower in 4 year old children (boys, $11.7 \%$; girls, 9.0\%) compared to 3 year old children (boys, 12.9\%; girls, 11.2\%) and 5 year old children (boys, 13.6\%; girls, $11.0 \%$ ) (all $\mathrm{p}<0.05$ ), possibly reflecting the adiposity nadir. Across racial/ethnic subgroups (Figure 1), the prevalence of obesity was highest among Hispanics (boys, 18.2\%; girls, 15.2\%) followed by blacks (boys, 12.4\%; girls, 12.7\%), $\mathrm{p}<0.05$ for within gender comparisons). Asian girls tended to have a lower prevalence (6.9\%) compared with white girls (7.9\%) $(\mathrm{p}=0.05)$, and Asian boys had a higher prevalence (10.9\%) compared with white boys $(8.6 \%)(\mathrm{p}<0.001)$. A total of $7.8 \%$ of children had BMI $\geq 97^{\text {th }}$ percentile, with a greater proportion among boys compared with girls $(9.1 \%$ versus $6.4 \%, \mathrm{p}<0.001)$ and the highest proportions in Hispanic children (13.9\% for boys; $10.4 \%$ for girls, Figure 1). Approximately half $(49.2 \%)$ of the children with BMI $\geq 97^{\text {th }}$ percentile also had a BMI $\geq 1.1 \times 95^{\text {th }}$ percentile. When categorized by BMI Z score 33.00 , only $0.3 \%$ of girls were identified compared to $2.0 \%$ of boys $(\mathrm{p}<0.001)$, with almost no girls identified by age 5 years $(0.1 \%)$.

Using BMI-for-age criteria for severe obesity, $1.6 \%$ of children had BMI $\geq 1.2$ times the $95^{\text {th }}$ BMI percentile (1.9\% for boys and $1.4 \%$ for girls, $\mathrm{p}<0.001$ ). This prevalence was significantly lower than that ascertained when using a threshold of BMI $\geqslant 99^{\text {th }}$ percentile (3.9\% overall, $5.1 \%$ for boys and $2.7 \%$ for girls, $\mathrm{p}<0.001$ ). For both thresholds, a male predominance was seen. Across racial/ethnic subgroups, Hispanic boys had the highest 
prevalence of severe obesity (3.3\%, $\mathrm{p}<0.01$ compared to boys of white, black or Asian race/ ethnicity and compared to Hispanic and black girls). Among girls, Hispanic and black girls had the highest prevalence of severe obesity ( $2.2 \%$ and $1.7 \%$, respectively, $\mathrm{p}<0.05$ when compared to white and Asian girls; $\mathrm{p}=0.30$ when comparing Hispanic and black girls).

Figure 2 shows the median height percentile by BMI percentile subgroup for each age by gender. Among children with BMI $<85^{\text {th }}$ percentile, the median height percentile was around the $50^{\text {th }}$ percentile. However, increasing BMI percentile category was associated with an increase in the median height percentile (significant linear trend, $\mathrm{p}<0.001$ ) within each age-sex stratum. Figure 3 shows the increasing proportions of children with BMI at or above the $95^{\text {th }}$ and $97^{\text {th }}$ percentiles across increasing height percentile in quintiles, $(p<0.001$, test for trend).

Included in this study were 223 children with extreme BMI (N=156) or both extreme BMI and weight $(\mathrm{N}=67)$ values that were correct despite identification by the $\mathrm{CDC}$-based program as high "biologically implausible values". As shown in Table 2, these included 3.5fold more boys than girls and the majority were of Hispanic or Asian race/ethnicity. All 223 children had BMI and weight percentile values in the $99^{\text {th }}-100^{\text {th }}$ percentile range, BMI Z score above 2.5, and BMI exceeding 1.2 times the $95^{\text {th }}$ BMI percentile for age and sex (Table 2). Each age-sex group also demonstrated extremely high median height percentiles ( $>80^{\text {th }}$ percentile). Although $0.9 \%$ had Prader-Willi syndrome, most did not demonstrate obesity-related conditions. The most prominent comorbidity was asthma, identified in $17.5 \%$ of this subgroup based on coded visit diagnoses in the prior six months.

We examined the frequency of overweight and obesity recognition over the ensuing year after the index well child visit in the 1,389 (12.3\%) of 11,274 children aged 5 years with BMI $\geq 95^{\text {th }}$ percentile because this age represents the beginning of the BMI trajectory beyond the adiposity nadir. The majority $(86.9 \%)$ had continuous membership for at least one year after the well-child visit, with one or more subsequent ambulatory visits among $76.5 \%$ overall and $80.2 \%$ for obese children. Among these 1,389 children, $71.0 \%$ had a visit diagnosis of either obesity or elevated BMI $\geq 95^{\text {th }}$ percentile and an additional $6.9 \%$ had a diagnosis relating to overweight (or BMI $85^{\text {th }}-94^{\text {th }}$ percentile), all of whom received routine nutrition and/or exercise counseling. There were 573 boys and 393 girls aged five years with BMI $\geq 97^{\text {th }}$ percentile in whom recognition of elevated BMI $\geq 95^{\text {th }}$ percentile and/or obesity was documented in $77.6 \%$. Among the subset of 173 boys and 118 girls with severe obesity (BMI $\geq 1.2 \times 95^{\text {th }}$ BMI for age percentile), recognition of elevated BMI $\geq 95^{\text {th }}$ percentile and/or obesity was higher at $89.0 \%$.

\section{Discussion}

In this cohort of more than 40,000 preschool-aged children (3-5 years old), $12.4 \%$ of boys and $10.0 \%$ of girls met criteria for obesity (BMI $\geq 95^{\text {th }}$ percentile). While fewer children met criteria for severe obesity defined by BMI $\geq 1.2$ times the $95^{\text {th }}$ percentile (1.6\%), the majority of obese children (69.5\%) exceeded the $97^{\text {th }}$ BMI percentile. Across increasing BMI strata, the prevalence was highest among Hispanic boys. These findings complement data from other studies demonstrating that the prevalence of high BMI-for-age in older children is 
greatest among Hispanic boys and African American girls. ${ }^{5,8}$ A study of 2,452 younger urban children similarly found that a disparity between Hispanic and non-Hispanic children can be identified as early as 3 years of age. ${ }^{29}$

This study found that in the context of routine pediatric care, a relatively high percentage of obese 5 year old children had their obesity recognized by their clinical caregivers, as ascertained from the electronic medical record; it is possible that recognition rates would have been even higher had all clinical encounter notes been systematically reviewed for this study. The proportion of children with subsequent outpatient visits during the ensuing year was also extremely high, suggesting there are opportunities to initiate preventive measures at this early age.

Both the $99^{\text {th }}$ BMI-for-age percentile threshold and a BMI threshold of 1.2 times the $95^{\text {th }}$ percentile have been used as measures of severe obesity. ${ }^{1,8-12}$ While the $99^{\text {th }}$ percentile identified a larger proportion of children, concerns have been raised about the accuracy of this threshold when using the CDC growth charts, given the lack of fit to empiric data. ${ }^{10}$ Furthermore, use of BMI percentile for stratification of extremely high BMI values is limited by contraction of percentile values at the upper bound where large changes in BMI result in minimal change in BMI percentile. ${ }^{30,31}$ The use of BMI Z score is also limited by an upper bound, depending on age and sex. ${ }^{31}$ Almost no girls aged 5 years had a $Z$ score $\mathbf{3} .00$, due to the fact that $\mathrm{Z}$ scores beyond 4.00 are undefined for girls and boys over the age of 4 and 6 years, respectively. ${ }^{31}$ These findings highlight challenges in classification of extremely high BMI-for-age in children, particularly for contemporary populations who represent a rightward shift from historic populations used for development of the year 2000 CDC growth charts. ${ }^{17}$ Classifying high BMI values as a percentage of the $95^{\text {th }}$ percentile has been proposed as a more flexible approach to characterizing obesity severity based on evidence that this approach provides a better fit to empiric data than BMI percentile estimates above the $97^{\text {th }}$ percentile. ${ }^{10}$ The currently preferred definition of severe obesity is a BMI $\geq 1.2$ times the $95^{\text {th }}$ percentile when using the CDC growth charts, ${ }^{10-12}$ a threshold that demonstrates better approximation of the empiric $99^{\text {th }} \mathrm{BMI}$ percentile. ${ }^{10}$ Consistent with these recommendations, a new growth chart based on BMI percentage above the $95^{\text {th }}$ percentile has recently been proposed for clinical tracking of severely obese children. ${ }^{32}$ Our study found that using a BMI threshold of $\geq 1.2 \times 95^{\text {th }}$ percentile identified $1.9 \%$ of boys and $1.4 \%$ of girls who met criteria for severe obesity. Because the range of BMI values within this young age group is relatively narrow compared to older children where the growth curves widen considerably, use of lower thresholds such as the $97^{\text {th }}$ percentile or $1.1 \times 95^{\text {th }}$ percentile may also be helpful in targeting young obese children at risk for progression to more severe degrees of obesity.

Most children initially flagged as having biologically implausible high values for BMI and/or weight had, in fact, valid measurements of these indices. More than three quarters were boys, of whom a large proportion were Hispanic (44\%) or Asian (25\%). The CDC program uses fixed exclusion ranges provided by the World Health Organization to define "biologically implausible values" with the goal of removing these excessively high values that may be due to entry errors or mis-measurement. ${ }^{27,} 28$ However, our findings demonstrate that values labeled as implausible should not be automatically excluded in 
young children without more careful evaluation of growth trajectory. Other investigators have used algorithms based on incremental weight or height values below the $1^{\text {st }}$ or above the $99^{\text {th }}$ percentiles to identify potential errors in the electronic medical record; ${ }^{33}$ using those methods in our study identified no additional children for exclusion. In this study, we used data from prior and/or subsequent clinical visits, where inconsistencies in measured height, weight and BMI within specific subgroups were used to determine the need for individual growth chart review.

Level of BMI was directly associated with height percentile, consistent with the known interrelationship of BMI and linear growth; heavier children were taller and those in the highest BMI category had the tallest stature. The increasing proportion of children with BMI $295^{\text {th }}$ percentile or $297^{\text {th }}$ percentile across increasing height quintiles is consistent with data from others who observed a more than 10-fold increase in obesity prevalence across lowest to highest height quintile for children 3-10 years of age. ${ }^{34}$ This early association between BMI and growth may have important implications for subsequent pubertal development, final adult height and adult adiposity. One of the challenges associated with assessment of adiposity status during the early years of growth is that changes in BMI represent both changes in adiposity and changes in lean mass. However, calculated BMI is strongly correlated with percent body fat measured by dual energy x-ray absorptiometry, ${ }^{35}$ and differences in BMI at a given height are associated with differences in body fatness. Additional demographic variation in the relationship of BMI to body fat may also be relevant when comparing BMI-for-age across different population subgroups. ${ }^{36}$

It is not clear whether obesity at this early age is related to differences in behaviors and feeding patterns, e.g., breast milk versus formula and the timing of introduction of solid foods, particularly in a racially and ethnically diverse cohort. Parental obesity, maternal conditions, environment and behavior are also known to modulate the risk of childhood obesity, ${ }^{37,38}$ but these contextual factors could not be ascertained in this study due to the limitations of the electronic medical record. Although this study did not include children under age 3 years, obesity trends may begin as early as infancy where examination of weight-for-length has been used to estimate the prevalence of infant obesity. ${ }^{39}$

In summary, the high prevalence of early onset obesity is of great concern from a public health perspective, because of the strong tracking effect of childhood obesity and relation of childhood obesity to adult metabolic complications and other clinical comorbidities. This concern is underscored by the finding that extreme obesity is significantly higher in specific ethnic groups and, in particular, Hispanics. While future research is needed to track the longterm outcomes among these children, the early recognition of obesity by healthcare providers and the high proportion with follow-up care within this young age group may provide an important framework to support delivery of effective and timely interventions for obesity management and prevention at an early age.

\section{Acknowledgments}

JL, BM, MC, SD, AS and LG conceived the project. MC conducted the data analyses. JL, BM and LG drafted the initial manuscript. All authors provided critical input on data analysis and interpretation, revised the manuscript for important intellectual content, and approved the final version. The authors would like to acknowledge Joel 
Gonzalez for his support with manuscript preparation. This study was funded by the National Heart, Lung and Blood Institute at the National Institutes of Health 1RO1HL093345 to HealthPartners Research Foundation (Patrick O'Connor, Principal Investigator) and conducted within the Cardiovascular Research Network, a consortium of research organizations affiliated with the HMO Research Network and sponsored by the National Heart Lung and Blood Institute (U19 HL91179-01).

\section{References}

1. Barlow SE. Expert committee recommendations regarding the prevention, assessment, and treatment of child and adolescent overweight and obesity: summary report. Pediatrics. 2007; 120(4):S164-92. [PubMed: 18055651]

2. Ogden, CL.; Lamb, MM.; Carroll, MD.; Flegal, KM. NCHS Data Brief. 2010. Obesity and socioeconomic status in children and adolescents: United States, 2005-2008; p. 1-8.

3. Ogden CL, Carroll MD, Curtin LR, Lamb MM, Flegal KM. Prevalence of high body mass index in US children and adolescents, 2007-2008. JAMA. 2010; 303:242-9. [PubMed: 20071470]

4. Ogden CL, Carroll MD, Kit BK, Flegal KM. Prevalence of Obesity and Trends in Body Mass Index Among US Children and Adolescents, 1999-2010. JAMA: The Journal of the American Medical Association. 2012

5. Ogden CL, Carroll MD, Flegal KM. High body mass index for age among US children and adolescents, 2003-2006. JAMA. 2008; 299:2401-5. [PubMed: 18505949]

6. Hedley AA, Ogden CL, Johnson CL, Carroll MD, Curtin LR, Flegal KM. Prevalence of overweight and obesity among US children, adolescents, and adults, 1999-2002. JAMA. 2004; 291:2847-50. [PubMed: 15199035]

7. Ogden CL, Carroll MD. Prevalence of obesity among children and adolescents: United States, Trends 1963-1965 through 2007-2008. NCHS Health E-Stat. 2010:1-5.

8. Skelton JA, Cook SR, Auinger P, Klein JD, Barlow SE. Prevalence and trends of severe obesity among US children and adolescents. Acad Pediatr. 2009; 9:322-9. [PubMed: 19560993]

9. Freedman DS, Mei Z, Srinivasan SR, Berenson GS, Dietz WH. Cardiovascular risk factors and excess adiposity among overweight children and adolescents: the Bogalusa Heart Study. J Pediatr. 2007; 150:12-7. e2. [PubMed: 17188605]

10. Flegal KM, Wei R, Ogden CL, Freedman DS, Johnson CL, Curtin LR. Characterizing extreme values of body mass index-for-age by using the 2000 Centers for Disease Control and Prevention growth charts. Am J Clin Nutr. 2009; 90:1314-20. [PubMed: 19776142]

11. Koebnick C, Smith N, Coleman KJ, et al. Prevalence of extreme obesity in a multiethnic cohort of children and adolescents. J Pediatr. 2010; 157:26-31. e2. [PubMed: 20303506]

12. Wang YC, Gortmaker SL, Taveras EM. Trends and racial/ethnic disparities in severe obesity among US children and adolescents, 1976-2006. Int J Pediatr Obes. 2011; 6:12-20.

13. Benson L, Baer HJ, Kaelber DC. Trends in the diagnosis of overweight and obesity in children and adolescents: 1999-2007. Pediatrics. 2009; 123:e153-8. [PubMed: 19117837]

14. Dietz WH. Critical periods in childhood for the development of obesity. Am J Clin Nutr. 1994; 59:955-9. [PubMed: 8172099]

15. Rolland-Cachera MF, Deheeger M, Bellisle F, Sempe M, Guilloud-Bataille M, Patois E. Adiposity rebound in children: a simple indicator for predicting obesity. Am J Clin Nutr. 1984; 39:129-35. [PubMed: 6691287]

16. Rolland-Cachera MF, Deheeger M, Maillot M, Bellisle F. Early adiposity rebound: causes and consequences for obesity in children and adults. Int J Obes (Lond). 2006; 30(4):S11-7. [PubMed: 17133230]

17. Kuczmarski, RJ.; Ogden, CL.; Guo, SS., et al. Vital Health Stat 11. 2002. 2000 CDC Growth Charts for the United States: methods and development; p. 1-190.

18. Demerath EW, Jones LL, Hawley NL, et al. Rapid infant weight gain and advanced skeletal maturation in childhood. The Journal of pediatrics. 2009; 155:355-61. [PubMed: 19446851]

19. Forbes GB. Nutrition and growth. The Journal of pediatrics. 1977; 91:40-2. [PubMed: 874662] 
20. Mamun AA, Hayatbakhsh MR, O'Callaghan M, Williams G, Najman J. Early overweight and pubertal maturation--pathways of association with young adults' overweight: a longitudinal study. International journal of obesity. 2009; 33:14-20. [PubMed: 18982007]

21. Must A, Naumova EN, Phillips SM, Blum M, Dawson-Hughes B, Rand WM. Childhood overweight and maturational timing in the development of adult overweight and fatness: the Newton Girls Study and its follow-up. Pediatrics. 2005; 116:620-7. [PubMed: 16099850]

22. Sandhu J, Ben-Shlomo Y, Cole TJ, Holly J, Davey Smith G. The impact of childhood body mass index on timing of puberty, adult stature and obesity: a follow-up study based on adolescent anthropometry recorded at Christ's Hospital (1936-1964). International journal of obesity. 2006; 30:14-22. [PubMed: 16344844]

23. Freedman DS, Khan LK, Serdula MK, Dietz WH, Srinivasan SR, Berenson GS. The relation of menarcheal age to obesity in childhood and adulthood: the Bogalusa heart study. BMC pediatrics. 2003; 3:3. [PubMed: 12723990]

24. Whitaker RC, Pepe MS, Wright JA, Seidel KD, Dietz WH. Early adiposity rebound and the risk of adult obesity. Pediatrics. 1998; 101:E5. [PubMed: 9481024]

25. Williams SM, Goulding A. Early adiposity rebound is an important predictor of later obesity. Obesity (Silver Spring). 2009; 17:1310. [PubMed: 19553922]

26. Daniels SR, Jacobson MS, McCrindle BW, Eckel RH, Sanner BM. American Heart Association Childhood Obesity Research Summit: executive summary. Circulation. 2009; 119:2114-23. [PubMed: 19332459]

27. [Accessed October 20, 2011] A SAS Program for the CDC Growth Charts. http://www.cdc.gov/ nccdphp/dnpao/growthcharts/resources/sas.htm

28. [Accessed April 26, 2012] Cut-offs to define outliers in the 2000 CDC Growth Charts. http:// www.cdc.gov/nccdphp/dnpa/growthcharts/resources/BIV-cutoffs.pdf

29. Whitaker RC, Orzol SM. Obesity among US urban preschool children: relationships to race, ethnicity, and socioeconomic status. Archives of pediatrics \& adolescent medicine. 2006; 160:578-84. [PubMed: 16754818]

30. Cole TJ, Faith MS, Pietrobelli A, Heo M. What is the best measure of adiposity change in growing children: BMI, BMI \%, BMI z-score or BMI centile? Eur J Clin Nutr. 2005; 59:419-25. [PubMed: 15674315]

31. Woo JG. Using body mass index Z-score among severely obese adolescents: a cautionary note. Int J Pediatr Obes. 2009; 4:405-10. [PubMed: 19922058]

32. Gulati AK, Kaplan DW, Daniels SR. Clinical tracking of severely obese children: a new growth chart. Pediatrics. 2012; 130:1136-40. [PubMed: 23129082]

33. Smith N, Coleman KJ, Lawrence JM, et al. Body weight and height data in electronic medical records of children. Int J Pediatr Obes. 2010; 5:237-42. [PubMed: 19961272]

34. Freedman DS, Khan LK, Serdula MK, Dietz WH, Srinivasan SR, Berenson GS. Inter-relationships among childhood BMI, childhood height, and adult obesity: the Bogalusa Heart Study. Int J Obes Relat Metab Disord. 2004; 28:10-16. [PubMed: 14652621]

35. Lindsay RS, Hanson RL, Roumain J, Ravussin E, Knowler WC, Tataranni PA. Body mass index as a measure of adiposity in children and adolescents: relationship to adiposity by dual energy x-ray absorptiometry and to cardiovascular risk factors. The Journal of clinical endocrinology and metabolism. 2001; 86:4061-7. [PubMed: 11549626]

36. Daniels SR, Khoury PR, Morrison JA. The utility of body mass index as a measure of body fatness in children and adolescents: differences by race and gender. Pediatrics. 1997; 99:804-7. [PubMed: 9164773]

37. Reilly JJ, Armstrong J, Dorosty AR, et al. Early life risk factors for obesity in childhood: cohort study. BMJ. 2005; 330:1357. [PubMed: 15908441]

38. Salsberry PJ, Reagan PB. Dynamics of early childhood overweight. Pediatrics. 2005; 116:1329-38. [PubMed: 16322155]

39. McCormick DP, Sarpong K, Jordan L, Ray LA, Jain S. Infant obesity: are we ready to make this diagnosis? J Pediatr. 2010; 157:15-9. [PubMed: 20338575] 


\section{What is already known about this subject}

- The prevalence of obesity in the U.S. has increased dramatically over the past 3 decades.

- There is a growing spectrum of severe obesity among children and adolescents.

- Obesity trends and race/ethnic differences may be evident at a young age.

\section{What this study adds}

- Among children age 3-5 years old, the prevalence of obesity and severe obesity was higher in boys than girls and highest among children of Hispanic ethnicity.

- Within this young age group, higher BMI was associated with greater height percentile.

- Among obese children age 5 years old, provider recognition of obesity or elevated body mass index was high, approaching $80 \%$ of children. 


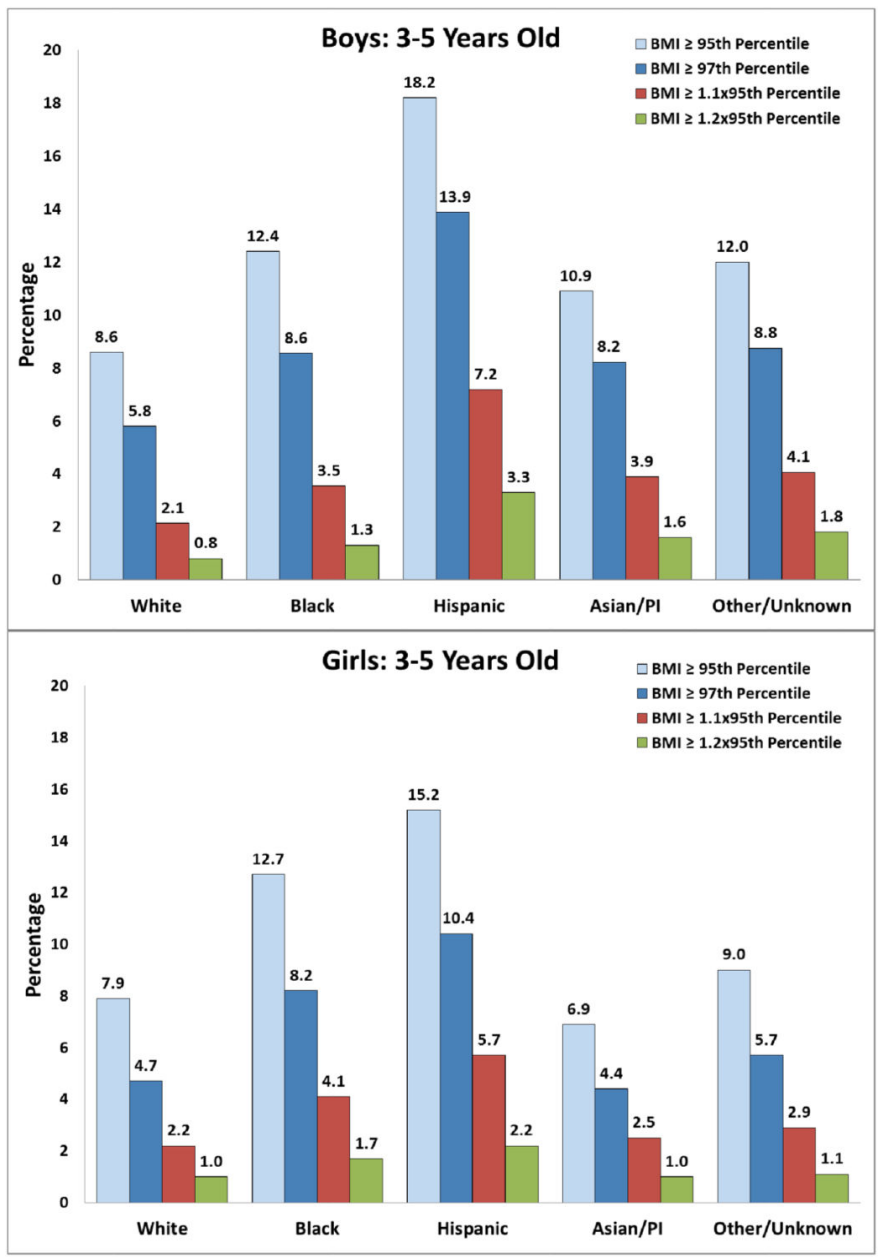

Figure 1. The proportion of children by sex and race/ethnicity according to BMI classification BMI $\geq 95^{\text {th }}$ percentile - obesity, BMI $\geq 1.2 \times 95^{\text {th }}$ percentile - severe obesity. 


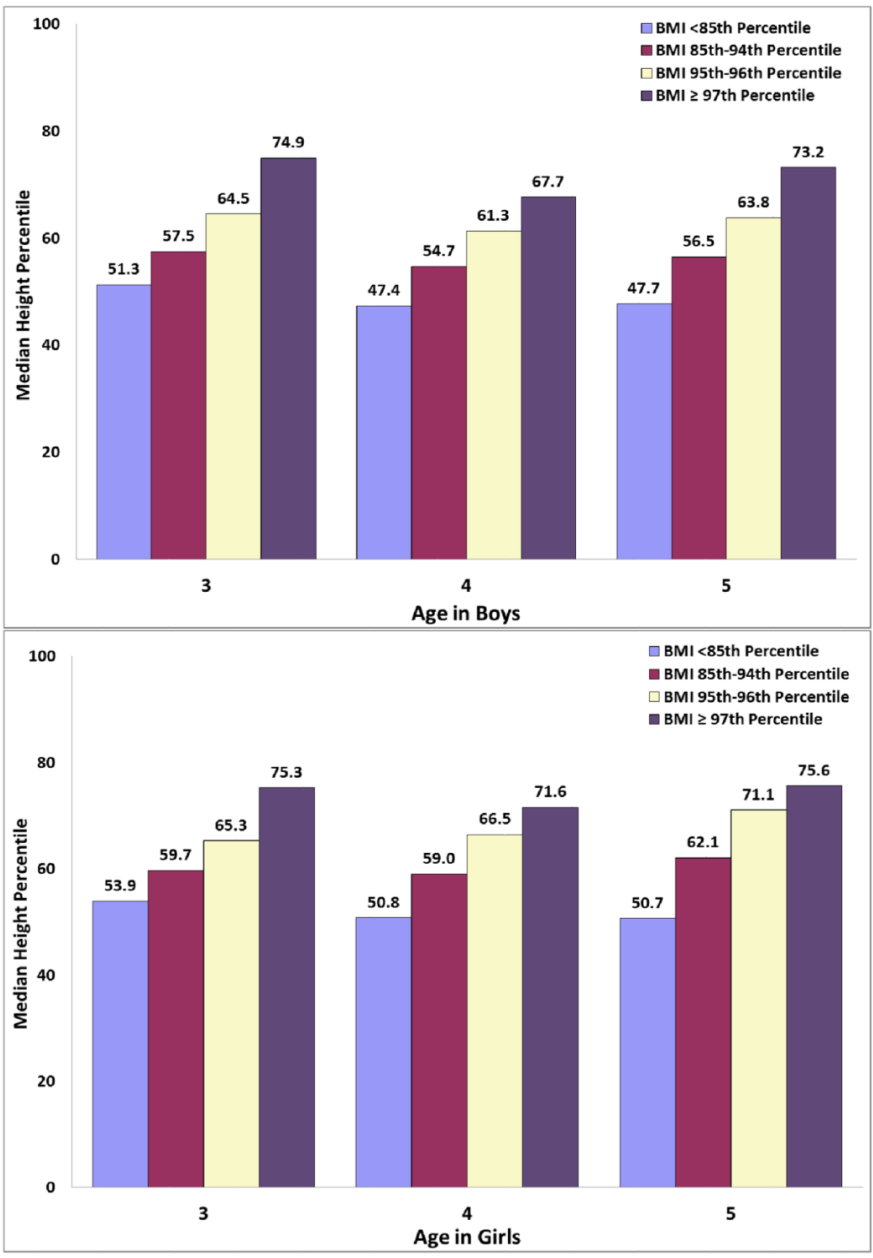

Figure 2. Median height percentile by body mass index (BMI) percentile in boys and girls Significant differences in median height percentile were seen across BMI categories for each age-sex stratum, with a significant linear trend $(\mathrm{p}<0.001$ within each age-sex category). 




Figure 3. Proportion of children with BMI $\geq 95^{\text {th }}$ percentile $\left(B M I 95^{\text {th }}-96^{\text {th }}\right.$ percentile or BMI $\geq$ $97^{\text {th }}$ percentile) by increasing height quintile in boys and girls age three to five years old $\mathrm{P}<0.001$ for trend across increasing height category. 


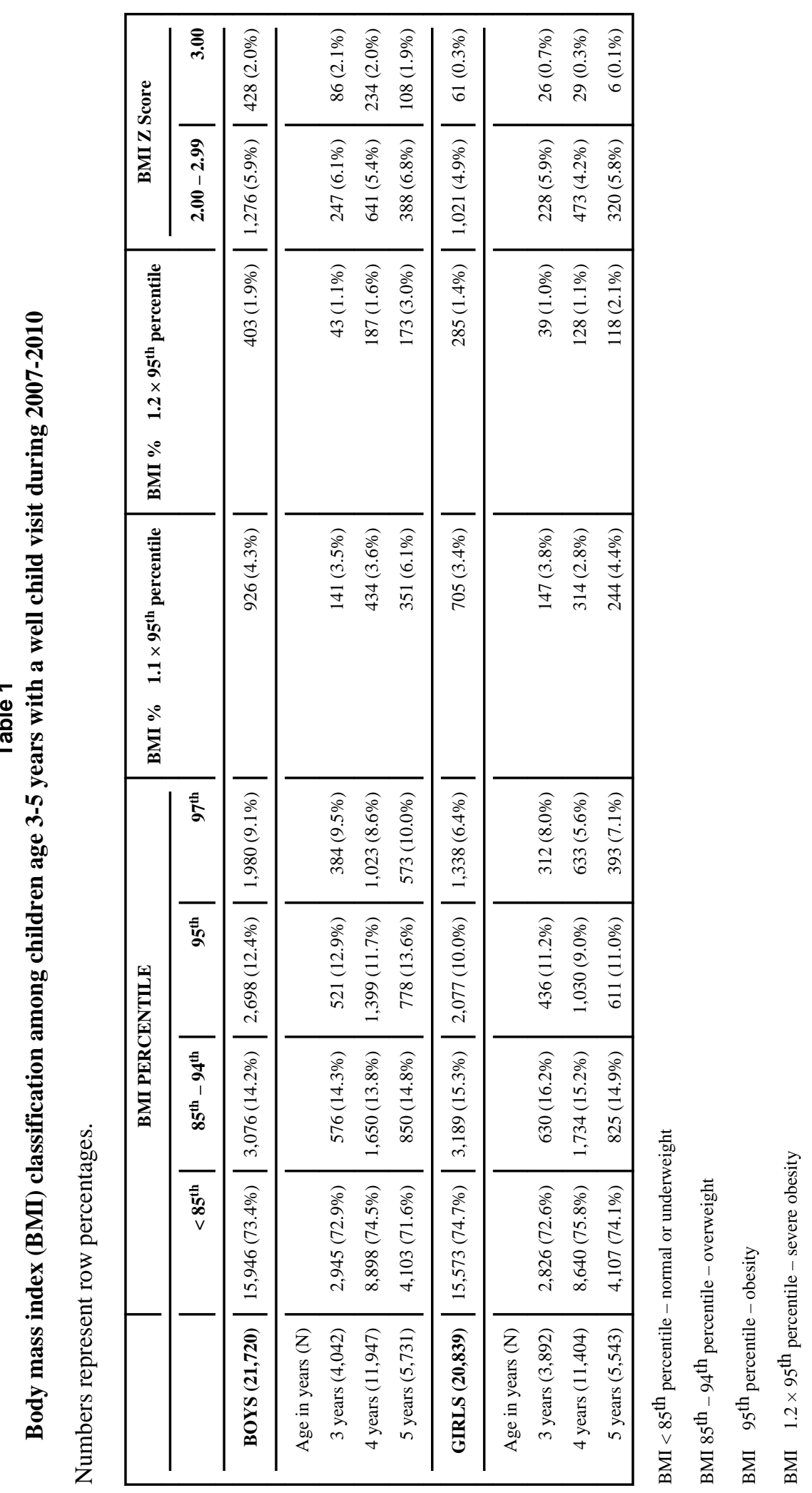

Pediatr Obes. Author manuscript; available in PMC 2015 June 01. 


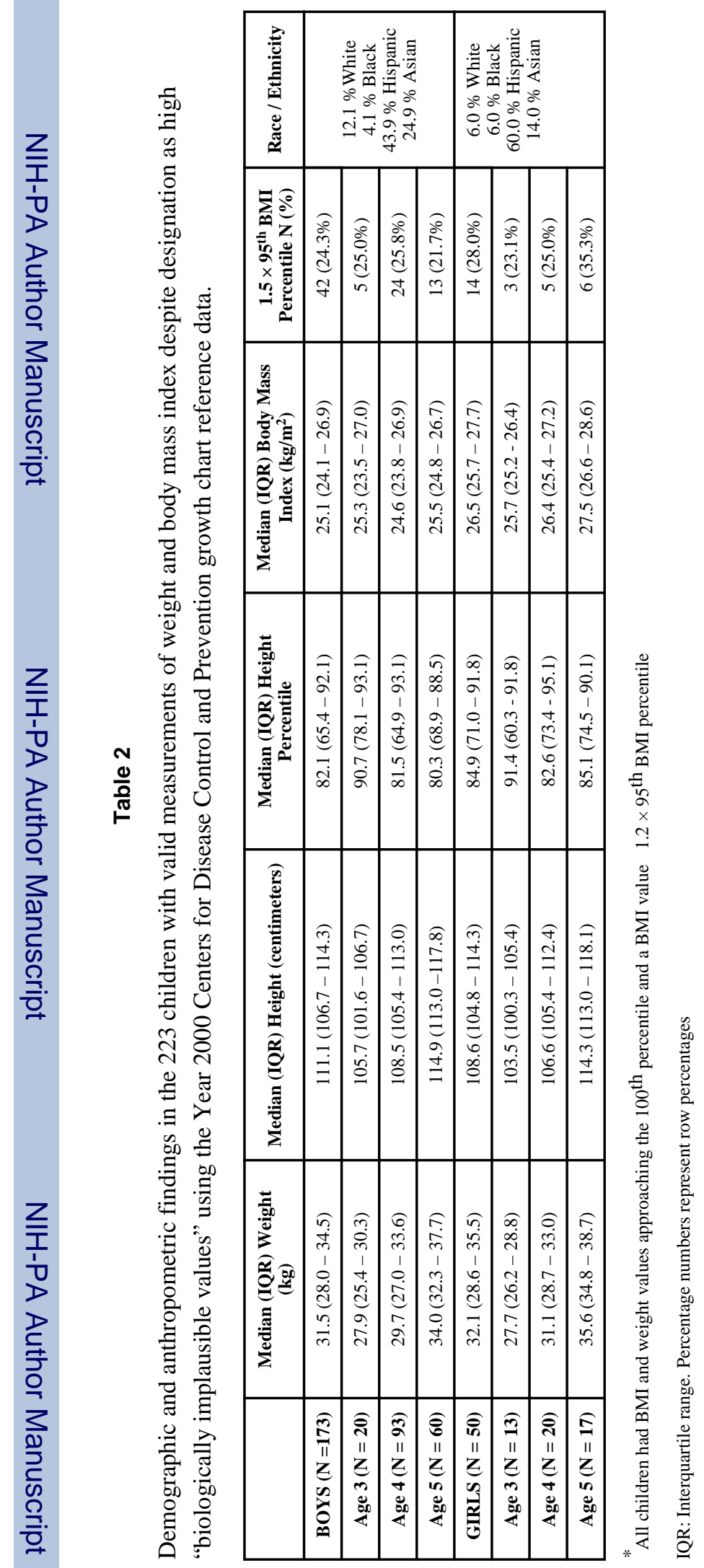

Pediatr Obes. Author manuscript; available in PMC 2015 June 01. 